\title{
Study of Sorption Kinetics of Doxycycline on pH Sensitive Hydrogel-based Graft Copolymers of Chitosan/Arabinogalactan/ Gummiarabic with Vinyl Monomers
}

\author{
MIRVARI KHALIG HASANOVA ${ }^{1,2}$ \\ 'Department of Nanostructured Metal-polymer Catalysist, Azerbaijan National Academy of Sciences, \\ Institute Catalysis and Inorganic Chemistry, H. Javid Ave.113, Baku, Azerbaijan, AZ1143, Azerbaijan. \\ ${ }^{2}$ SOCAR Polymer LLC, Quality laboratory engineer \\ ${ }^{*}$ Corresponding author E-mail: mirvari.hs.chem@gmail.com \\ http://dx.doi.org/10.13005/ojc/370612
}

(Received: September 22, 2021; Accepted: November 16, 2021)

ABSTRACT

Graft copolymers of natural polysaccharides chitosan (Chs), gummi-arabic $(G A)$ and arabinogalactan $(A G)$ were synthesized with $\mathrm{N}$-vinylpyrrolidone $(V P r)$ (4-vinylpyridine and $\mathrm{N}$-vinylpyrrolidone used as comonomers for chitosan grafting), and then $\mathrm{pH}$-sensitive hydrogels were designing by cross-linked them with $\mathrm{N}, \mathrm{N}$-methylene-bis-acrylamide. Effective sorption of doxycycline from aqueous solutions with water-swelling gels has been studied experimentally. The effect of gel dose, initial concentration of doxycycline, $\mathrm{pH}$ medium and solution ionic strength of the sorption rate and capacity of the antibiotic was systematically studied. The surface and volume absorption kinetics and isotherms of the process have also been investigated. It was found that the max sorption capacity for swellable gels varies between Chs-graft-VPr/4VP>AG/graft-VPr>GA/ graft-VPr. It has been shown that the sorption mechanism is mainly dominated by physical sorption and to some extent hydrogen bonds and electrostatic interactions.

Keywords: Chitosan, Gummiarabic, Arabivogalactan, Graft copolymer, Hydrogel, Doxycycline, Sorption.

\section{INTRODUCTION}

It is known that antibiotics are widely used in modern medicine in the treatment of inflammatory diseases, destruction or inhibition of bacterial cells ${ }^{1,2}$. Doxycycline (Dox) is one of the anthracycline series of antibiotics which is currently used in inflammatory diseases of the respiratory and gastrointestinal tract $^{3-5}$. Dox is a broad-spectrum antibacterial drug consisting of free $-\mathrm{OH},-\mathrm{NH}_{2}$ and carbonyl groups. Doxycycline is a semi-crystalline antibiotic and is used to treat superficial diseases of the eye, periodic epithelial erosion, and corneal wounds ${ }^{6-8}$.

Sorption of antibiotics by ion exchange materials is widely used in their separation and purification processes. There is also some scientific research in the periodical literature on the sorption of antibiotics by polymer sorbents and the study of thermodynamics and kinetics of the process ${ }^{9,10}$. The inclusion of drugs in polysaccharide macromolecules not only reduces their adverse effects on the body,

This is an Open Access article licensed under a Creative Commons license: Attribution 4.0 International (CC- BY). Published by Oriental Scientific Publishing Company @ 2018

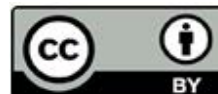


but also increases their bioavailabilities.

In addition, some drugs pollute the environment after use, which has a detrimental effect on humans, animals and plants ${ }^{11,12}$. Dox is widely used in agriculture, causing more environmental pollution ${ }^{13}$. It is known that this antibiotic is not fully absorbed and $30-90 \%$ of the dose is excreted without biological activity ${ }^{14}$. Separation of Dox from polluting water to prevent such adverse effects is an actual topic. Research on its adsorption of Dox on organic, inorganic and hybrid polymeric materials can be found in the literature ${ }^{15-20}$.

From this point of view, the effective removal of Dox with natural polymer-based hydrogels is an urgent problem. The synthesis of new types of hydrogel materials is of great interest. In the literature, sorption of Dox with Chs, GA and AG-based hydrogels is highly preferred. Because these polymers have great potential in the industry and we can briefly mention the following about them. $A G$ is a hyperbranched natural polysaccharide which has gasprotector, membrane-conducting and high sorption capacity properties. It is widely used as a carrier of enzymes, drugs and essential minerals for the human body. The AG macromolecule has a highly branched structure (Fig. 2): the main chain consists of a galactose chain connected by a $\beta-(1 \rightarrow 3)$ glucoside bond. The side chain is composed of uronic acids, mainly glucuronic acids, which bind to the galactose and arabinose links by a $\beta-(1 \rightarrow 6)$ bond $^{21-24}$.

Chs is a polycationite type natural linear structural polyaminosaccharide obtained from chitin by deacetylation process. Chitosan is composed of randomly distributed of $\beta$ - $(1,4)-2$-amino-2-deoxyglucosamine and $\beta$ - $(1,4)-\mathrm{N}$-acetyl glucosamine units $^{25-27}$. The high sorption capacity due to metal ions, non-toxicity, and drugs, and easily chemical functional of Chs macromolecules confirm that its perfect chemical and physical properties in delivery of biological active compounds in biotechnology and stabilization of antibacterial metal nanoparticles ${ }^{28-31}$.

$G A$, a natural polysaccharide, is a biologically inert polymer used in medicine to make soft and hard capsules and to make high sorption adsorbents. The GA macromolecule has a hyber branch chemical structure (Fig. 2). Its elemental link consists of pentose, methyl pentose, hexose and polyuronic acid units combined with each other ${ }^{32,33}$. The main skeleton of the $G A$ macromolecule is composed of galactose and mannose, and the side branches are composed of pentose and xylose units. In the present study, $\mathrm{pH}$-sensitive gels were synthesized from the cross-linking of Chs $\mathrm{VPr}$ and 4VP graft copolymer with glutaraldehyde, and $G A$ and $A G$ VPr graft copolymer cross-linked with $M B A A$. The structural characteristics of the gels were studied and the sorption isotherms of doxycycline were investigated. The parameters of antibiotic separation from the aqueous solution were also determined and the sorption results were applied in different kinetic models.

\section{EXPERIMENTAL}

ChS (deacetylation degree and average molecular weight are $87-90 \%$ and $35 \mathrm{kDa}$, respectively), $A G$ and $G A$ were obtained from Sigma Aldrich ( $A G, 200 \mathrm{kDa}$; GA $400 \mathrm{kDa}$ ). Glacial acetate acid, acetone ( $\geq 99.8 \%)$, ethanol (95\%), diethyl ether ( $\geq 99.6 \%$ ) and MBAA also from Sigma-Aldrich co Itd. As initiator used 2,2-azobisisobutyronitrile $(A I B N)$ and $4 V P$ (assay 95-96\%), $\operatorname{VPr}(\geq 99 \%)$ were also purchased from Acros Organics and had been distilled and recrystallization before the use. All solvents were purified by distillation, according to the conventional methods and were purchased from Sigma Aldrich. Dox with the empiric chemical formula $\mathrm{C}_{22} \mathrm{H}_{24} \mathrm{~N}_{2} \mathrm{O}_{8} \times \mathrm{HCl} \times 0.5 \mathrm{H}_{2} \mathrm{O} \times 0.5 \mathrm{C}_{2} \mathrm{H}_{6} \mathrm{O}$ was obtained from Merck.

\section{Gel preparation}

ChS (AG or GA) is dried at $40-50^{\circ} \mathrm{C}$ (24 h) suspended by $150 \mathrm{~mL}$ of $2 \% \mathrm{CH}_{3} \mathrm{COOH}$, then 1-2 hmixing. $2 \mathrm{~mL}$ monomer's - VPr and $4 V P$ (1:1 mol ratio) were added to the Chs solution and continuously stirred in $30 \mathrm{~min}$ (VPronly for $A G$ and $G A)$. The reaction was performed according to the method $^{21}$. Graft-natural polysaccharides (graft-Np) copolymer samples are mixed with a cross-linking reagent and gelation obtained within $30 \mathrm{~min}$ $\left(65-75^{\circ} \mathrm{C}\right)$. Prepared all three natural based hydrogels were washed with bidistilled water and ethanol, respectively ${ }^{21}$. 


\section{Characterizations}

The infrared properties of the Chs, $A G$ and $G A$ graft copolymer based hydrogel and hydrogelsDox simples were analysis by Fourier transforms infrared spectrophotometer (FTIR) in the 4000-400 $\mathrm{cm}^{-1}$ range by Nicolet 6700 , (USA) instrument. Nanosized Zetasizer ZS90, Mulvern instrument used for measurements of surface zeta potential of obtained hydrogels. The initial and equilibrium concentrations of Dox in aqueous solution were determined by an ultraviolet spectrophotometer at $349 \mathrm{~nm}$ (UV-Vis 2550, Shimadzu, Japan).

\section{Adsorption experiments}

The doxycycline removal experiments for the three different hydrogel samples were conducted with a $90 \mathrm{mg} / \mathrm{L}$ initial concentration ${ }^{16}$. Ten $\mathrm{mL}$ of the antibiotics solution was mixed with natural based hydrogel $(4 \mathrm{mg})$ at different $\mathrm{pH}$, removal times, and temperatures. The samples were filtered with specific filters from Millipore prior. The calibration curves of various antibiotics concentrations were established from 10;20; 40; 60 and $90 \mathrm{mg} / \mathrm{L}$ concentrations with best linearity in all circumstances.

Adsorption isotherms for the all hydrogel simples performed the following method. Ten $\mathrm{mL}$ solutions of the neutral $\mathrm{pH}$ antibiotics solution with different concentrations $(10,20,40,60$ and $90 \mathrm{mg} / \mathrm{L})$ were mixed and stirred at $20^{\circ} \mathrm{C}$ temperature with the hydrogel graft-Np (4 mg) at different contact times for Dox antibiotic. Equilibrium condition determination experimentally, for the Dox adsorption according to the method ${ }^{34}$. Concentrations of antibiotics were determined as described above due to the method. Adsorption capacity of graft-Np, Qe, was calculated according to Eq.1:

$Q_{e}=\frac{\left(C_{0}-C_{t}\right)}{m} \times V$

Where, $Q_{e}$ - is the equilibrium Dox sorption capacity (mg/gr), $C_{0}$ is initial and $C_{e}$ is the equilibrium concentrations of antibiotics (mg/L), $V=10 \mathrm{~mL}$ is the volume of Dox solutions, and $\mathrm{m}$ is of the graft-Np dose by $\mathrm{mg}$.

\section{RESULT AND DISCUSSION}

In a previous study ${ }^{21}$ author obtained the optimal graft co-polymer reaction condition of radical copolymerization of $\mathrm{VPr}$ and $4 \mathrm{VP}$ into $\mathrm{ChS}$ macromolecule. For this graft co-polymers synthesis, $M B A A$ as a specific cross-linker was prepared. The new $\mathrm{pH}$ sensitive hydrogels could form after chemical binding of graft-ChS-PVPr-co-P4VP simples with $M B A A$ by radical reaction. This covalent binding occurred between $-\mathrm{CH}_{2}$ groups of $P V P r$, $-\mathrm{NH}_{2}$ groups of $\mathrm{ChS}$ and $-\mathrm{CH}<$ groups on $P 4 P V$. A possible radical chemical reaction mechanism of co-grafting could be shown in Fig. 1 by the author ${ }^{21}$.

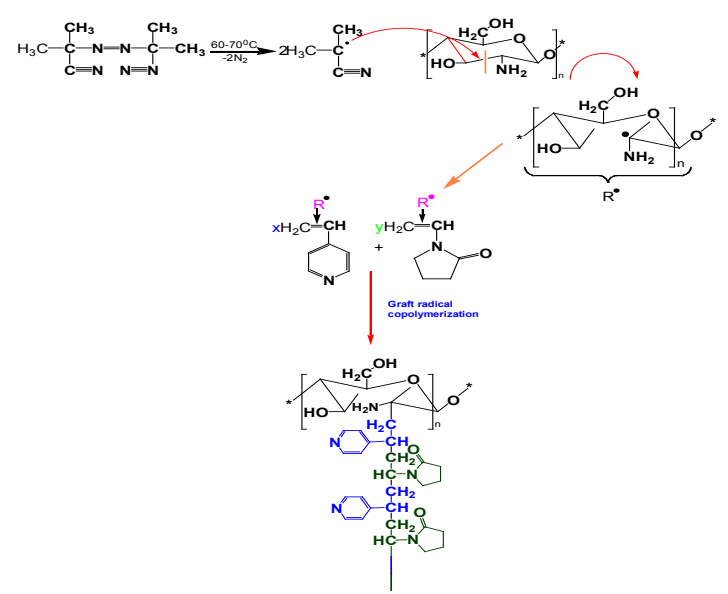

Fig. 1. The chemical co-graft radical polymerization reaction of VPr and $4 V P$ vinyl monomers with Chs chains

The FT-IR spectrum of ChS was characterized by intensive widespread peaks in 1656 and $1598 \mathrm{~cm}^{-1}$ of $-\mathrm{NH}_{2}$ groups. The peak which is observed in $1260 \mathrm{~cm}^{-1}$ region belongs to $\mathrm{C}-\mathrm{N}$ binding on Chs. The bands of characteristics for saccharide structure are at $1157 \mathrm{~cm}^{-1}$ (C-O-C), 1087 and 1032 $\mathrm{cm}^{-1}(\mathrm{C}-\mathrm{O})^{25}$. The $-\mathrm{NH}_{2}$ group has a shift from 1598 $\mathrm{cm}^{-1}$ to 1578 and $1578 \mathrm{~cm}^{-1}$ region in the spectra of the cross-linked CS based gel. Similar experiments were performed with $V P r$ monomers of $A G$ and $G A$, and copolymer samples with similar structure were synthesized. The cross-linking of these copolymer samples with $M B A A$ resulted in the formation of hydrogels that can be swollen in water and $\mathrm{pH}$ medium. The synthesis and characterization of such hydrogels have been studied in detail in the work of Shamo et al., ${ }^{23,24}$. In the structure, it is possible to imagine the chemical structure of the sample of graft copolymer obtained by replacing the Chs units with fragments $A G$ and $G A$. Dox binding mainly occurred between $-\mathrm{OCOCH}_{3},-\mathrm{COOH}$ on Dox and $-\mathrm{OH},-\mathrm{NH}$ groups of $\mathrm{ChS}$ the by hydrogen bond. Other chemical shifts involving $\mathrm{C}-\mathrm{O}$ chemical stretching on Chs from 1755, 1087 and $1032 \mathrm{~cm}^{-1}$ to 1732, 1069 and 1024 $\mathrm{cm}^{-1}$ were due to that intermolecular hydrogen bond between Dox and Chs. 
Addition, the FTIR spectra of $G A$ and $A G$ for the adsorption of Dox typical chemical peaks of polymer chains observed in different regions. In 3430 $\mathrm{cm}^{-1}$ peak concerning aromatic connected $\mathrm{O}-\mathrm{H}$, $1620 \mathrm{~cm}^{-1}$ of benzene ring $\mathrm{C}=\mathrm{C}$ bonds, $1390 \mathrm{~cm}^{-1}$ to -COO-, and $1090 \mathrm{~cm}^{-1}$ intensive peak belongs to $\mathrm{C}-\mathrm{O}-\mathrm{C}$ bonds. After the adsorption of Dox, the peaks at $400-800 \mathrm{~cm}^{-1}$ interval belonged to the aromatic $-\mathrm{CH}$ chemical group of antibiotics, proposed that the antibiotic molecule was adsorbed onto the hydrogel surface layer. The peak shifted from 3430 $\mathrm{cm}^{-1}$ to $3440 \mathrm{~cm}^{-1}$ belongs to $\mathrm{O}-\mathrm{H}$, the peaks shifted from 1390 to $1430 \mathrm{~cm}^{-1}$ belongs of $-\mathrm{COO}-$ and the peaks shifted from $1090 \mathrm{~cm}^{-1}$ to $1100 \mathrm{~cm}^{-1}$ belongs to alkoxy C-O-C bonds after adsorption of Dox molecules. The double of $\mathrm{C}=\mathrm{C}$ bonds peaks about to the aromatic group shifted from 1622 to $1631 \mathrm{~cm}^{-1}$ region after complexes of the Dox, show that the p-p electron-donor acceptor chemical force between Dox molecules and hydrogels was proposed as the important parameter for drug adsorption ${ }^{40,41}$.

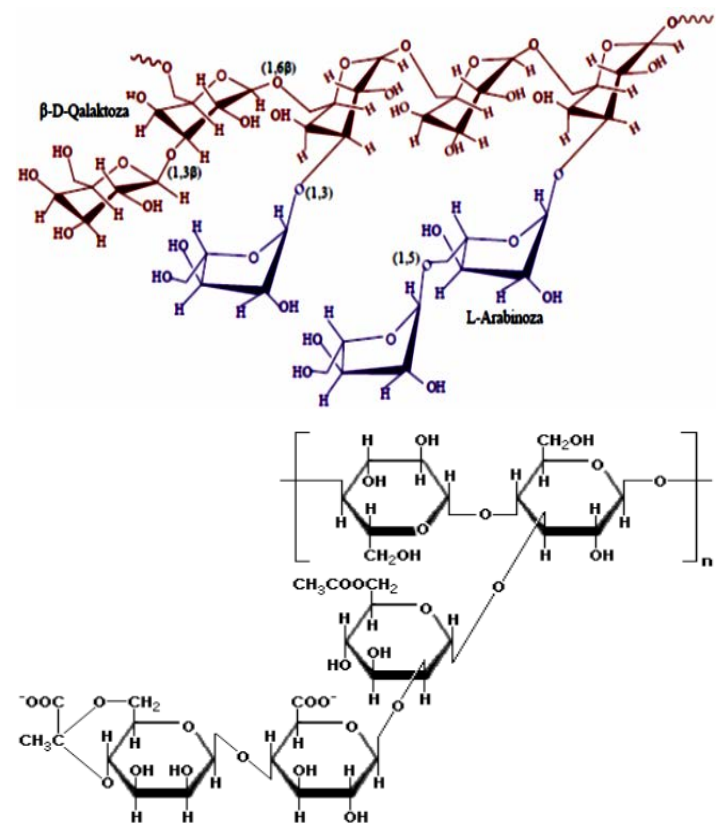

Fig. 2. Chemical structure of arabinogalactan (top) and gummiarabic (following)

The effect of the dose of hydrogels and the $\mathrm{pH}$ medium on the removal of the Dox antibiotic from the aqueous solution (Fig. 4). The degree of removal of Dox by $A G$ and GA graft copolymer based gels is the same. Removal occurs at a higher degree in Chs graft with VPrand 4VP copolymer based gels. This is due to the richness of the main macromolecule in terms of functional groups and the presence of
4VP units in the Chs chain. The pyridine ring binds to Dox with $\pi \rightarrow \pi$ interaction. In $A G$ and $G A$-based gel samples, the Dox interaction is mainly due to hydrogen bonding and electrostatic attraction ${ }^{36}$.

The effect of $\mathrm{pH}$ of the medium and dose of gel simple on Dox removal was studied in detail (Figure 3).
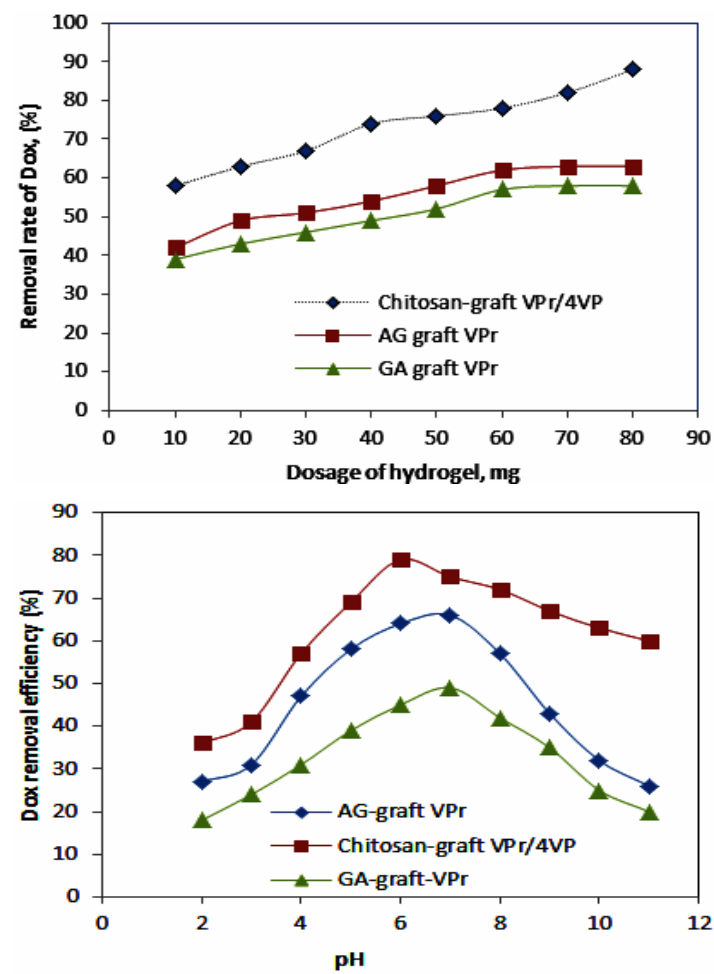

Fig. 3. The effect of the dose of hydrogel and the $\mathrm{pH}$ of the medium on the sorption of Dox. $20 \mathrm{mg} / \mathrm{L}$ was initial concentration of Dox, temperature $298 \mathrm{~K}$ and contact time was 24 hours

Shown that, the removal efficiency of Dox depends on from the solution $\mathrm{pH}$, initially increased and then began decreased. Graft-Nps exhibited higher antibiotic capacity at neutral $\mathrm{pH}$. According to the sorption result, the adsorption of Dox was highly $\mathrm{pH}$-dependent, and the cross-linking chains of the hydrogels played an important role in antibiotic sorption. The medium of the $\mathrm{pH}$ affected the hydrogel top layer charge and also the Dox dispensation in solution. It is clear that, graft-Nps carried various $\mathrm{O}$-containing $-\mathrm{COOH}$ and hydroxyl functional groups. Most of these chemical functional groups are positively charged due to the protonated acidic $\mathrm{pH}$ medium. The hydrogel surface's chemical functional groups will become the deprotonation and negatively charged at higher $\mathrm{pH}$. 
It's known that Dox has multiple $-\mathrm{OH}$, $-\mathrm{C}_{6} \mathrm{H}_{4}-\mathrm{OH},-\mathrm{NH}_{2}$ ionisable chemical functional groups hence can exist as an cation, anion and a zwitterion. This also makes it possess multiple values for $\mathrm{pKa}$ (acid dissociation constant). Between intermediate $\mathrm{pH}$ values it exists as a zwitterion ${ }^{34,35}$. When the pKa1 $=3.02$ at $\mathrm{pH}<3.02$ Dox exists as a Dox $x^{+}$. When $\mathrm{pK}_{\mathrm{a} 2}=7.97$ at $3.02<\mathrm{pH}<7.97$ medium antibiotic exists as a Dox . Between pH 7.97 and 9.15 it exists as Dox - and $\mathrm{pK}_{\mathrm{a} 3}=9.15$ and also $\mathrm{pH}>9.15$ due to the $-\mathrm{C}_{6} \mathrm{H}_{4}-\mathrm{CO}-\mathrm{O}$ - moiety and tri-C=O system loss of protons antibiotic as an $D o x^{2-}$. The three different ionisable forms of Dox functional groups are shown in Figure 4.

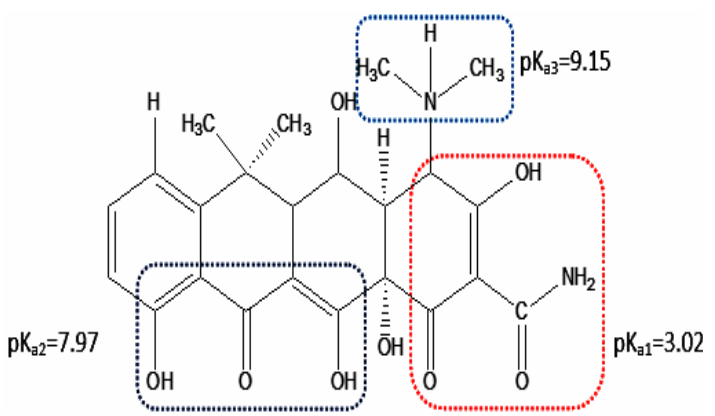

Fig. 4. The positions of different ionisable chemical functional groups of Dox chemical structure at different $\mathrm{pK}_{\mathrm{a}}$

The main form of Dox molecules would be zwitter-ionic and cationic types at $\mathrm{pH} \leq 7$, and this form is effectively available for $p \rightarrow p$ electro-donor acceptor chemical interaction. This interaction formed with the pyridine ring structures of the Chs based hydrogel. When the $\mathrm{pH}$ values increase, Dox molecules begin to deprotonation and results decrease the $\pi$-withdrawing ability of the group. In addition, the electrostatic repulsion between the anionic form of Dox molecules and the functional groups deprotonated of natural based hydrogels increased with increasing $\mathrm{pH}$ values. At the end this leads to a decrease in sorption capacity.

The effect of $\mathrm{Na}^{+}$and $\mathrm{Cl}^{-}$ions and nonelectrolyte concentration on the sorption of Dox by hydrogel samples is shown in Figurs 5 .

As can be seen, the antibiotic capacity of the $A G$ and $G A$-based gel sorbents decreases as the concentration of $\mathrm{NaCl}$ in the solution increases. In Chs based gel, the antibiotic capacity increases to a concentration of $4 \mathrm{mg} / \mathrm{L}$ and then begins to decrease. However, the effect of electrolyte concentration on Dox sorption by Chs based gel is not so sharp. It seems that the interaction between the antibiotic molecule and the gel is stronger, and the concentration of $\mathrm{Na}^{+}$and $\mathrm{Cl}^{-}$ions up to $10 \mathrm{mg} / \mathrm{L}$ has little effect on the weakening of these interactions. Such a strong interaction is due to the presence of a pyridine ring in the structure. Which proves the existence of the interaction $\pi \rightarrow \pi$ in this system. In $A G$ and $G A$-based gel samples, the antibiotic capacity of the gel begins to decrease by more than $20 \%$ as the electrolyte concentration increases. Because in this case, the chemical bond does not occur, as in Chs.
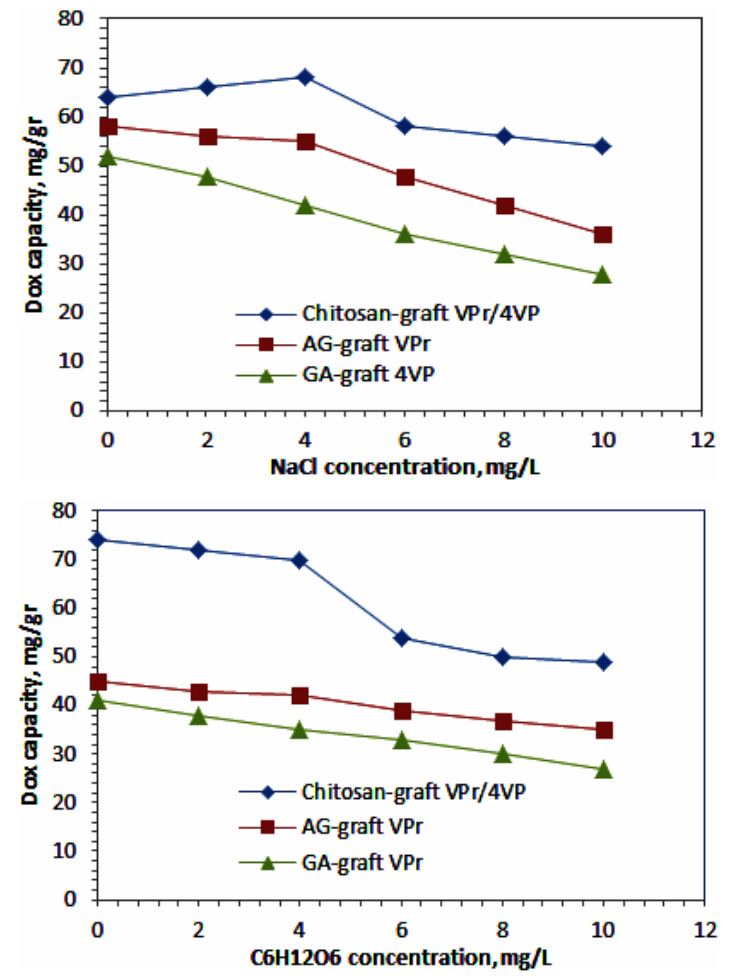

Fig. 5. The effects of $\mathrm{NaCl}$ and glucose concentration of Dox sorption by Chs-graft-VPr/4VP, AG-graft-VPr and $G A-g r a f t-V P r$ based hydrogel sorbents. $C_{D o x}=40 \mathrm{mg} / \mathrm{L}$; hydrogel dose $=\mathbf{4 0} \mathrm{mg} ; \mathrm{T}=\mathbf{2 9 8} \mathrm{K}$; contact time $=\mathbf{2 4}$ hours

It is known that adsorption isotherms characterize the distribution of adsorbate molecules in different equilibrium concentrations in the liquid phase on the surface of a solid substrate. Thus, by applying the adsorption results to different isothermal models, it is possible to determine the nature of the interaction between the adsorbate molecule and the hydrogel. In this case, the perfect adsorption models are the Freundlich and Langmuir models (Fig. 6), and the linear dependence forms of these models are expressed by equations (1) and (2) below. 
$\frac{C_{e}}{Q_{e}}=\frac{1}{Q_{m} K_{L}}+\frac{C_{e}}{Q_{m}}$

$L_{n} Q_{e}=L_{n} K_{F}+\frac{1}{n} L_{n} C_{e}$

Where $\mathrm{C}_{\mathrm{e}}$ - is the concentration of Dox in equilibrium condition, $\mathrm{mg} / \mathrm{L}, \mathrm{Q}_{\mathrm{e}}$ - is the amount of Dox adsorbed per gram of natural based hydrogel graft- $\mathrm{Np}$ at equilibrium condition, $\mathrm{mg} / \mathrm{gr}$, $Q_{m}$ is the maximum adsorption capacity which is calculated by theoretical by graft-Np for Dox, $\mathrm{mg}$ / $\mathrm{gr}, K_{L}$ is a constant of Langmuir isotherm, $1 / \mathrm{mg}, \mathrm{K}_{\mathrm{F}}$ is the empirical constant for Freundlich adsorption isotherm of the graft- $N p$, and $1 / n$ is a the Freundlich adsorption constant.
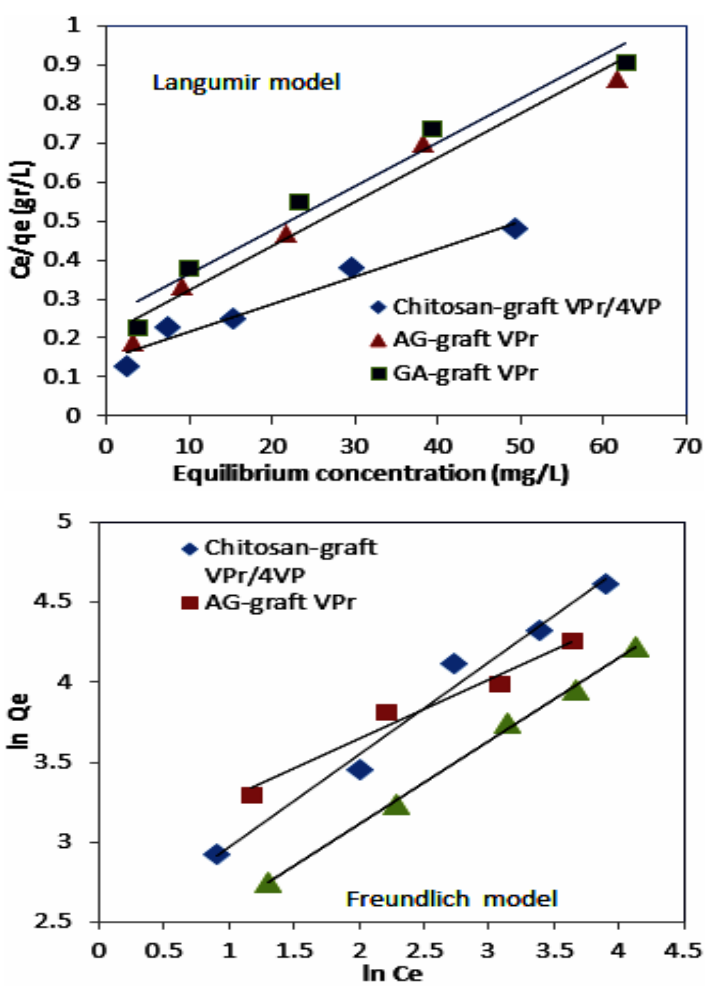

Fig. 6. Langmuir and Freundlich adsorption isotherms for Dox sorption by natural polysaccharide based hydrogel sorbent

The adsorption data of the studied Dox molecules onto graft-Nps were fitted with the Langmuir and Freundlich isotherms (Fig. 6). These two models, which can provide information on the 2 important parameters: adsorption capacity and affinity. The adsorption of Dox happened in a homogeneous surface of the natural based hydrogels according to the Langmuir model. But according to the Freundlich model the adsorption is not reversible, occurring by formation of multilayers of graft-Nps on a hydrogel surface ${ }^{36,37}$. The Freundlich model the best fitted for the adsorption process by Chs and AG-graft polymers based gel according to the $\mathrm{R}^{2}$ correlation coefficient (Table 1). But Dox sorption data is best fitted with the Langmuir and Freundlich models for the $G A$ based graft copolymer gel.

Table 1: Parameters of Freundlich and Langmuir isotherm models of Dox sorption with natural polysaccharide based gels

\begin{tabular}{lcccc}
\hline Hydrogel simples & Model & $\mathrm{K}_{\mathrm{L}}$ or $\mathrm{K}_{\mathrm{F}} \mathrm{Q}_{\mathrm{m}}(\mathrm{mg} / \mathrm{gr})$ & $\mathrm{R}^{2}$ \\
& & \multicolumn{4}{c}{ or $1 / \mathrm{n}$} \\
\hline Chitosan-graft VPr/4VP & Langumir & 17.54 & 19 & 0.960 \\
& Freundlich & 1.06 & 0.052 & 0.982 \\
AG-graft VPr & Langumir & 5.05 & 18 & 0.965 \\
& Freundlich & 1.01 & 0.048 & 0.998 \\
GA-graft $V P r$ & Langumir & 3.27 & 17 & 0.968 \\
& Freundlich & 0.98 & 0.059 & 0.971 \\
\hline
\end{tabular}

The $1 / n$ values of the constant were less than 1 due to the Freundlich model, and this indicated suitable adsorption process (Table 1). The $Q_{m}$ - highest adsorption capacity for the Chs based graft copolymer, which was found to follow the physical-sorption mechanism adsorption of Dox. According to $R_{L}=1 /\left(1+K_{L} C_{0}\right)$ equation Langmuir constant $\mathrm{K}_{\mathrm{L}}$ can be calculated and presented in Table 1. The dimensionless separation factors calculated for Chs graft copolymer based gel is 0.006 . The values of $\mathrm{R}_{\mathrm{L}}$ for $A G$ and $G A$ based copolymer gels are 0.019 and 0.029 , respectively. If the $R_{L}$ datas were greater than zero and less than 1 , these results showed favorable adsorption.

Forming stable adsorption and an effective system requires full understanding of the dynamic process of the sorption reaction. By using two kinetic models-pseudo-first order-PFO(4) and pseudosecond order-PSO (5) linear forms were applied of the studied of the adsorption kinetics of Dox systems (Figure 7):

$\operatorname{Ln}\left(Q_{e}-Q_{t}\right)=\operatorname{Ln} Q_{e}-K_{1} t$

$\frac{t}{Q_{t}}=\frac{1}{K_{2} Q_{e}^{2}}+\frac{t}{Q_{e}}$

Where, $Q_{e}$ is the adsorption capacity of antibiotics at the equilibrium state and $Q_{t}$ is adsorption capacity of antibiotics at time of $t$; the $P F O$ and $P S O$ adsorption modulus are $\mathrm{K}_{1}(1 / \mathrm{min})$ and $\mathrm{K}_{2}(\mathrm{~g} / \mathrm{mg} \times \mathrm{min})$, respectively. 

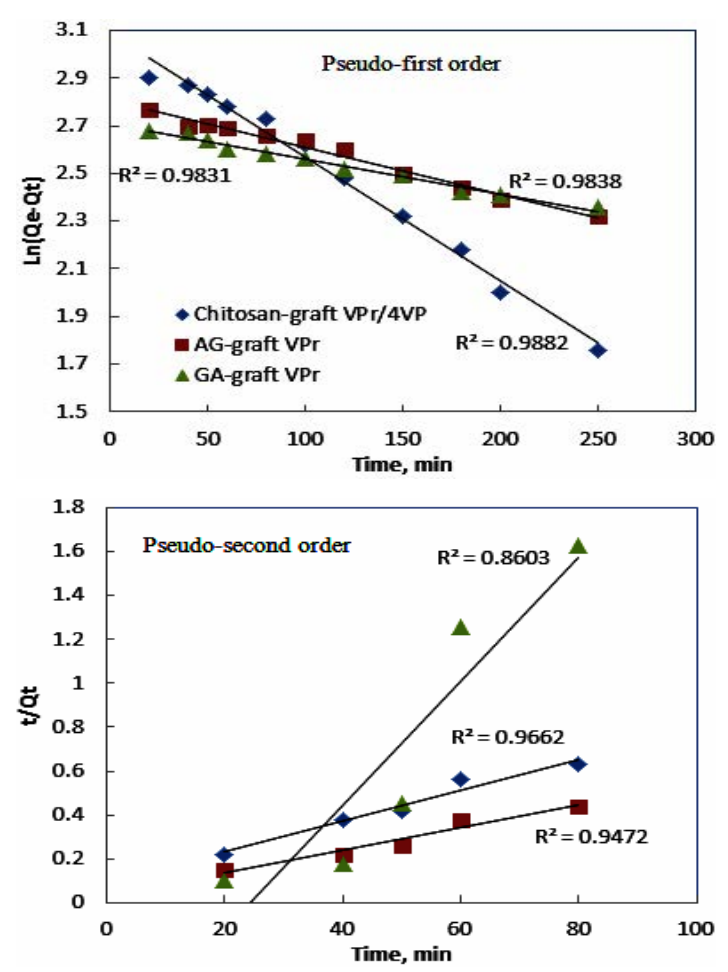

Fig. 7. Adsorption-PFO and PSO kinetic models data of the sorption of the Dox on natural based polysacharides

The $\mathrm{R}^{2}$ correlation coefficient was 0.966 of the PSO model for Chs based hydrogels, and this data indicates the adequacy of this fitting model. The meaning of this finding is that the adsorption of Dox by $C h s$ based hydrogel is assumed to be kinetically controlled as a $S O$ reaction and the adsorption is dependent on the dose of natural based hydrogel and concentrations of Doxmolecules. According to the PSO rate constant data the chemical adsorption mechanism involves electrostatic mutual attraction for $A G$ and $G A$ graft copolymer based hydroge ${ }^{37}$.

Thermodynamic parameter is necessary to determine the spontaneity or otherwise of an adsorption process. $\Delta \mathrm{G}^{\circ}$-Gibbs free energy, $\Delta \mathrm{H}^{\circ}$ enthalpy, $\Delta S^{\circ}$-entropy change, etc., are important useful thermodynamic parameters. These first three parameters are critically important for predicting adsorption mechanisms and thermodynamics, for the characterization and optimization of an adsorption process. The basic $\Delta \mathrm{G}^{\circ}, \Delta \mathrm{H}^{\circ}$, and $\Delta \mathrm{S}^{\circ}$ thermodynamic parameters were evaluated by (6)-(8) equations.

$$
\begin{aligned}
& \Delta \mathrm{G}=-\mathrm{RT} \text { LnK } \\
& L n K=\frac{\Delta S}{R}-\frac{\Delta H}{R T} \\
& \Delta \mathrm{G}^{0}=\Delta \mathrm{H}^{0}-\mathrm{T} \Delta \mathrm{S}^{\circ} \\
& K_{d}=\frac{Q_{e}}{C_{e}}
\end{aligned}
$$

Where, $\mathrm{K}$ are Langmuir and Freundlich isotherm constant, $\mathrm{L} / \mathrm{mol} ; \mathrm{R}=8.314 \mathrm{~J} / \mathrm{mol} \times \mathrm{K}$ is the universal gas constant. The plot of InK values against $1 / T$, will give $\Delta H^{\circ}$, and $\Delta S^{\circ}$ as the incline and intercept, respectively. The typical thermodynamic values for Dox adsorption onto different hydrogel are shown in Tables 2. Effect of temperature of adsorption process were conducted at 283, 2293, 303 and $313 \mathrm{~K}$ in $3 \mathrm{~h}$ and determined the following thermodynamic parameters.

Table 3: Thermodynamic parameter of Dox by natural based graft copolymer hydrogel

\begin{tabular}{lccccc}
\hline Polymer hydrogel & Temperature, $(\mathrm{K})$ & $\mathrm{K}_{\mathrm{d}}$ (Dimensionless) & Average $\Delta \mathrm{G}^{\circ}\left(\mathrm{KJ} \times \mathrm{mol}^{-1}\right)$ & $\Delta \mathrm{H}^{\circ}\left(\mathrm{KJ} \times \mathrm{mol}^{-1}\right)$ & $\Delta \mathrm{S}^{\circ}\left(\mathrm{J} \times \mathrm{mol}^{-1}\right)$ \\
\hline Chs-graft VPr/4VP & 283 & 1.47 & -0.91 & 0.001 & 0.0032 \\
& 293 & 7.5 & -4.99 & 0.067 & 0.0169 \\
& 303 & 3.05 & -2.81 & 0.161 & 0.0098 \\
AG-graft $\mathrm{VPr}$ & 313 & 1.36 & -0.79 & -0.015 & 0.0025 \\
& 283 & 2.48 & -2.14 & -0.018 & 0.0075 \\
& 293 & 5.31 & -4.14 & 0.035 & 0.0140 \\
& 303 & 9.34 & -5.62 & 1.247 & 0.018 \\
GA-graft $\mathrm{VPr}$ & 313 & 3.49 & -3.25 & 0.502 & 0.012 \\
& 283 & 2.19 & -1.84 & -0.024 & 0.006 \\
& 293 & 4.25 & -3.58 & -0.011 & 0.012 \\
& 303 & 7.20 & -4.96 & -0.114 & 0.016 \\
\hline
\end{tabular}

Table 2 showed that Dox adsorption onto different natural based hydrogels was predominantly an endothermic process. The endothermic nature of the sorption process suggests the possibility of multiple displacements of solvent molecules sequel to Dox adsorption onto the hydrogel surfaces and volume pores. Table 2 showed that the Dox adsorption was mostly physical $\left(0<\Delta \mathrm{H}^{\circ}<20 \mathrm{KJ} / \mathrm{mol}\right)$, 
except for few studies that are predominated by physical-chemical adsorption. A positive $\Delta S^{\circ}$-value implies high hydrogel-Dox affinity during adsorption. Known that, $\mathrm{pH}$ medium changes the charges of hydrogel surfaces and drug molecules. From the Fig. 8 showed that at pH lower than the isoelectric point, hydrogels are positively charged. The $\mathrm{pH}$ higher from the isoelectric point gels in a negatively charged. The adsorption of Dox molecules occurs on the top layer phase of the hydrogel surface based on the surface potential data.
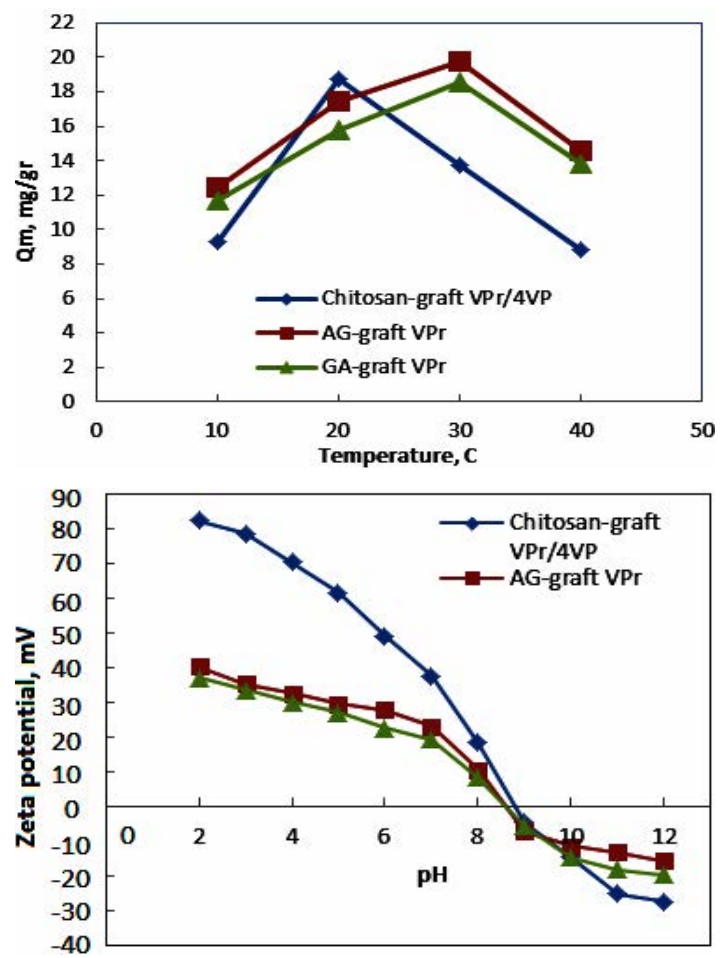

Fig. 8. Temperature depended on the adsorption of Dox by Chs, $A G$ and $G A$ based hydrogel and zeta potential of these hydrogels as a function of $\mathrm{pH}$

The Dox antibiotic could chemical and physical interact more strongly with Chs-graft copolymer hydrogel surfaces with strong $\pi \rightarrow \pi$ electro-donor acceptor interaction. It showed that Chs-graft copolymer exhibited more sorption affinity for Dox molecules than by $A G$ and $G A$ based graft copolymer gels. Ch-graft copolymer structured more aromatic cycles and hydroxyl groups than $A G$ and $G A$, which provide more $\pi \rightarrow \pi$ electro-donor acceptor interaction opportunities for Dox. Other hand, the hydrophilicity of Chs-graft copolymer based hydrogel was much less than that of AG-graft VPr and GAgraft VPr based hydrogels.

\section{CONCLUSION}

The specific chemical and physical sorption mechanism of doxycycline antibiotic adsorption onto Chs, $A G$ and $G A$ based hydrogels were thoroughly investigated. The isothermic values are well fitted by the Freundlich model for all experiments. Kinetic experiments showed that sorption data were best described by the pseudo-second order model. Adsorption process at different $\mathrm{pH}$ medium data's confirmed that the sorption of antibiotic from medium by $C h s, A G$ and $G A$ based gels could be occurred by positive-negative charge interactions. This repulsion interaction occurred in the aromatic cycles and charged functional groups between the hydrogel and doxycycline. According to the data of the $\Delta G^{\circ}$ energy the sorption process is spontaneous. Finally, the study showed that Chs-garft-VPr-co-4VP is capable of removal of doxycycline antibiotic from the aqueous solution $(85-88 \%)$ at the optimized conditions and these matrices can be used as potential drug delivery in biotechnology.

\section{ACKNOWLEDGEMENT}

The author Mirvari Hasanova is thankful to the author Shamo Tapdigov Oilgasresearchdesign Institute SOCAR for affording scientific assistance to the research work.

\section{Conflicts of interest}

The author declares that there is no conflict of interest in the present research work.

\section{REFERENCES}

1. Bao, Y.; Li, F.; Wen, D. H. Mar. Environ. Sci., 2021, 40, 294-302.

2. Cao, J.; Liu, F.; Liu, S.; Wang, J.; Zhu, B.; Shi, Y. Sci. China Life Sci., 2021, 1-4.

3. Francini, E.; Miano, S.T.; Fiaschi, A.I.; Francini, G. Med. Hypotheses., 2020, 144, 110054.
4. Chowdhury, A.T.M.M.; Shahbaz, M.; Karim, R.; Islam, J.; Dan, G.; Shuixiang, H. Eurasian J. Med. Oncol., 2021, 5, 63-70.

5. Mosquera-Sulbaran, J.A.; HernándezFonseca, H. Arch. Virol., 2021, 166, 1-7.

6. Sija, A.; Payal, M. Orient. J. Chem., 2019, 35, (3), 1086-1093. 
7. Gendrot, M.; Andreani, J.; Jardot, P.; Hutter, S.; Delandre, O.; Boxberger, M.; Mosnier, J.; Le Bideau, M.; Duflot, I.; Fonta, I. Molecules., 2020, 25, 5064.

8. Waleed, K.A.; Safaa, H.G.; Makarim, A.M.; Layth, S. J. Inter. J. Applied Pharm., 2020, 12(6), 100-106.

9. Alnajrani, M.N.; Alsager, O. A. Sci. Rep., 2020, 10(1), 1-14.

10. Tian, Z.; Tian, Z.; Zhang, Y.; Xiao, L.; Chen, Ch.; Mark, J.G.; Harry, R.A. Polymer Chemistry., 2013, 4, 1826-1835.

11. Palli, L.; Spina, F.; Varese, G.C.; Vincenzi, M.; Aragno, M.; Arcangeli, G.; Mucci, N.; Santianni, D.; Caffaz, S.; Gori, R. Int. J. Hyg. Environ. Health., 2019, 222, 717-725.

12. Olarinmoye, O.; Bakare, A.; Ugwumba, O.; Hein, A. J. Environ. Chem. Ecotoxicol., 2016, 8(3), 14-24.

13. Peng, P.C.; Wang, Y.; Liu, L.-Y.; Liang, J.-B.; Wu, Y.-B. Poult. Sci., 2016, 95(5), 1033-1041.

14. Fan, Y.; Zheng, C.; Hou, H. Environ. Eng. Sci., 2019, 36,(9), 1027-1040.

15. Baran, W.; Adamek, E.; Jajko, M.; Sobczak, A. Chemosphere., 2018, 194, 381-389.

16. Zaidi, S.; Chaabane, T.; Sivasankar, V.; Darchen, A.; Maachi, R.; Msagati, T.; Prabhakaran, M. Proc. Saf. Env. Prot., 2016, 102, 450-461.

17. Ai, X.; Fan, H.; Wang, Y.; Guo, Y.; Liu, X.; Yang, L.; Liu, H.; Yang, J. RSC Adv., 2018, 8(63), 36280-36285.

18. Gao, J.; Gao, Y.; Sui, Z.; Dong, Z.; Wang, S.; Zou, D. J. Alloy. Compd., 2018, 732, 43-51.

19. Bolobajev, J.; Trapido, M.; Goi, A. Chemosphere., 2016, 153, 220-226.

20. Igwegbe, C.; Umembamalu, C.; Osuagwu, E.; Oba, S.; Emembolu, L. Eur. J. Sustainable Dev. Res., 2021, 5(1), https:// doi.org/10.29333/ejosdr/9285.

21. Tapdigov, Sh.Z. Cellulose Chemistry and Technology., 2020, 54(5-6), 429-438.

22. Federico, L.H.; Tryphona, T.; Annaliza, R.; Yu, X.L.; Matthew, O.B.H.; Alex, A.R.W.; Kotake, T.; Paul. D. Plant Cell., 2020, 32(10), 33463369.

23. Tapdiqov, Sh.Z.; Zeynalov, N.A.; Taghiyev, D.B.; Humbatova, S.F.; Mammedova, S.M.; Nasiyyati, E.F.; Babayeva, D.T. J.Chem.Soc. Pakistan., 2015, 37, 1112-1118.
24. Tapdiqov, Sh.Z.; Zeynalov, N.A.; Humbatova, S.F.; Nagiev, Ch.A.; Isazadeh, A.; Hasanova, M.Kh.; Safaraliyeva, S. Asian J. of Chemistry., 2015, 28, 189-193.

25. Tapdigov, Sh. Z. Macromolecules Research., 2021, 29(2), 120-128.

26. Tapdigov, Sh.Z. Orient. J. Chem., 2020, 36(2), 254-261.

27. Selvakumar, M.; Thomas, S. Journal of Polymer Science., 2021, 59, 1610-1642.

28. Kumar, M. N. V. R.; Muzzarelli, R. A. A.; Muzzareilli, C.; Sashiwa, H.; Domb, A. J. Chemical Review., 2004, 104, 6017-6084.

29. Nafisa, G.; Shahzad, M.K.; Osama, B.M.; Atif, I.; Attaullah, Sh.; Sehrish, J.; Saba, U.Kh.; Afrasyab, Kh. Intern. Jour. of Biolog. Macromolecules., 2020, 162, 175-187.

30. Pierklaz, K.; Tylman, M.; Zofia, M. Mini Rev. In Med. Chemistry., 2020, 16, 1619-1632.

31. Martyna, Z.; Patrycja, K.; Ewa, O.; Ramona, F.; Marcin, S. Int. J. Mol. Sci., 2021, 22(7), 3339.

32. Henrique, P.M.; Andre, R.F. Journal of Envir. Manag., 2020, 288(6), 112455.

33. Mi, L.; Li, H.; Xianguang, L.; Hua, Z.; Xu, Z.; Lianqing, L.; Jianjie, M.; Mingjun, Z. ACS Appl. Mater. Interfaces., 2017, 9(27), 22160-22175.

34. Chao, Y.; Zhu, W.; Wu, X.; Hou, F.; Xun, S.; Wu, P.; Ji, H.; Xu, H.; Li, H. Chem. Eng. J., 2014, 24, 360-367.

35. Liu, S.J.; Liu, Y.G.; Tan, X.F.; Liu, S.B.; Li, M.F.; Liu, N.; Yin, Z.H.; Tian, S.R.; Zhou, Y.H. J. Chem. Technol. Biotechnol., 2019, 94(7), 2187-2197.

36. Kong, Y.; Wang, L.; Ge, Y.; Su, H.; Li, Z. J. Hazard. Mater., 2019, 368, 33-41.

37. Vijayaraghavan, K., Padmesh, T.; Palanivelu, K.; Velan, M. J. Hazard. Mater., 2006, 133, 304-308.

38. Mohammed, B.K.; Dekhyl, A.B.; Himdan, T.A. J. Educ. Sci. Stud., 2017, 4(10), 135-150.

39. Chowdhury, S.; Mishra, R.; Saha, P.; Kushwaha, P. Desalination., 2011, 265, 159-168.

40. Li, H.; Wu, W.; Hao, X.; Wang, S.; You, M.; Han, X.; Qing, Z.; Baoshan, X. Environ. Pollut., 2018, 243, 206-217.

41. Nekouei, F.; Nekouei, S.; Kargarzadeh, H. Chem. Eng. J., 2018, 335, 567-578. 